\title{
防波堤周囲の流れの実験と数值 Simulation
}

\section{1. 序論}

海岸に波が斜めに入射する場合，沿岸流が発達する. この様な海岸に防波堤等の構造物を設置すると, 沿岸流 の流況がどのように変化し，循環流がどの様に誘起され るかは興味ある問題で, その解明は海岸地形の侵食堆積 現象や，温排水の放水問題などを考える上で基礎的な情 報になるものと期待される. この問題の処理の困難さは 反射波の存在にあり，Liu and $\mathrm{Mei}^{11}$ は斜面勾配が一様 と言う制約があるものの，その解決法の一例を提出して いる. 本論文ではこの方法を基礎にし，数值計算と実験 結果を対比しつつ, 突堤周井の流れの特性について報告 する.
丸 山康 樹*. 鹿島 遼 一*

側の流速を測定した．座標系は沖方向に $x$ 軸, 原点を突 堤位置として汀線方向に $y$ 軸，鉛直上方を $z$ 軸とする. $H_{0}$ は表一1 を参考にして $2 \mathrm{~cm}$ とした. 測定結果を図 -1 に示すが, 沿岸流が $y=-3 \mathrm{~m}$ 付近で岸から剝離 し，突堤に沿って沖にほぼ真直に流出する．突堤と剝離 点とで形成される三角形領域に，反射波による砕波線の 変動に伴う循環流が形成され，砕波帯の狭い所から流れ が沖に向う.

\section{3. 防波堤周囲の波高計算}

突堤により反射波の発生する側をUP-WAVE REGION, 反対側を DOWN-WAVE REGION と呼ぶ. $\mathrm{Liu}$ and $\mathrm{Mei}^{11}$ は緩勾配斜面上の波長の変化を考慮した

表一1 沿 岸流 の測定結果

\begin{tabular}{|c|c|c|c|c|c|c|c|}
\hline Case & $\begin{array}{c}\text { 沖波波高 } \\
H_{0}(\mathrm{~cm})\end{array}$ & $\begin{array}{c}\text { 砕 波 点 } \\
x_{B}(\mathrm{~cm})\end{array}$ & $\begin{array}{c}\text { 砕波波 高 } \\
H_{B}(\mathrm{~cm})\end{array}$ & $\begin{array}{c}\text { 最大 run up } \\
r(\mathrm{~cm})\end{array}$ & $\begin{array}{c}\text { 最大流速 } \\
v_{\max }(\mathrm{cm} / \mathrm{sec})\end{array}$ & $P$ & $\begin{array}{l}\text { 摩 擦 係 数 } \\
C_{f}\left(\times 10^{-2}\right)\end{array}$ \\
\hline 1 & 2.90 & 220 & 3.52 & 19.2 & 18.0 & 0.316 & 0.535 \\
\hline 2 & 1.94 & 170 & 2.68 & 14.6 & 13.1 & 0.158 & 0.714 \\
\hline 3 & 1.34 & 120 & 1.85 & 11.1 & 8.9 & 0.138 & 0.774 \\
\hline
\end{tabular}

\section{2. 流れの実験}

基礎資料を得るため，沿岸流の発生実験を最初に行っ た. $30 \mathrm{~m} \times 35 \mathrm{~m}$ の平面水槽内に, 勾配 $S=1 / 50$ のモル タル製斜面を製作し，沖波入射角 $\theta_{0}$, 周期 $T$ をそれぞ れ $60^{\circ}, 1.2 \mathrm{sec}$ とし, 沖波波高 $H_{0}$ を変化させて実験 を行った. 実験法は Galvin and Eagleson²)を参考にし， Longuet-Higgins $^{3)}$ にならってデータを整理した結果を 表一1 に示した. $P$ から換算した摩擦係数 $C_{f}$ は一定 でなく，H $H_{0}$ が小さいほぼ大きくなる．砕波帯内の波高 分布は

$$
H=2 \gamma h
$$

と仮定した時, 3 case とも $\gamma=0.34$ で良く近似できる. 次に突堤による沿岸流の影響を調べるために，堤長 4 $\mathrm{m}$ の模型を沿岸流が充分発達した位置に配置し, 反射波

* 正会員 工修 電力中央研究所土木技術研究所 環境水理部

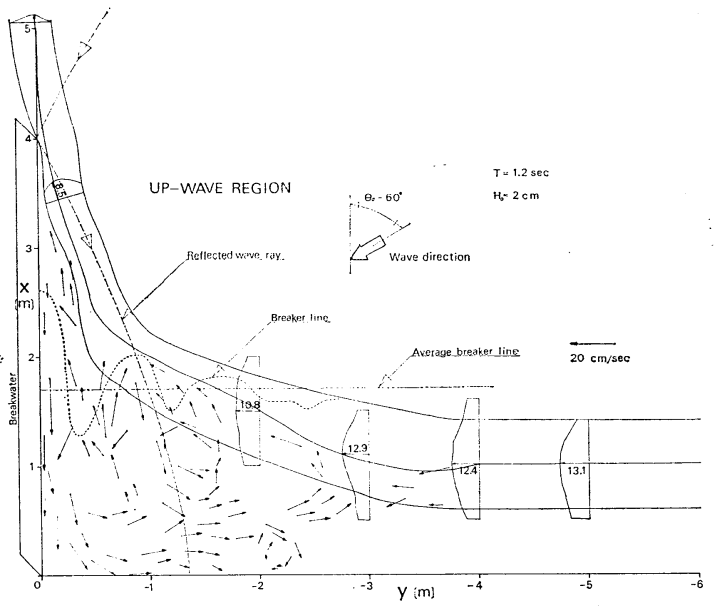

図一1 流れの測定結果

回折波を解いている. 詳細は論文 ${ }^{1}$ を参照するとして， 入射波と反射波を合成した解の結果だけを記すと， 


$$
\begin{aligned}
\Phi= & -i \frac{g A}{\omega} \frac{\cosh k(z+h)}{\cosh k h} \\
& \times \exp \left\{-i\left(\int^{x} \alpha d x^{\prime}+\omega t-\Theta\right)\right\} \\
A= & a|D|=a_{0} K_{s} K_{r}|D|, \\
|D|= & {\left[1+\frac{1}{2}\left\{\frac{1}{2}+c(\sigma)\right\}^{2}+\frac{1}{2}\left\{\frac{1}{2}+s(\sigma)\right\}^{2}\right.} \\
& +\sqrt{2}\left\{\frac{1}{2}+c(\sigma)\right\} \cdot \cos \left(2 \beta y+\frac{\pi}{4}\right) \\
& \left.+\sqrt{2}\left\{\frac{1}{2}+s(\sigma)\right\} \cdot \sin \left(2 \beta y+\frac{\pi}{4}\right)\right]
\end{aligned}
$$

となり， $\alpha, \beta$ は波数べクトルで，それぞれ，

$$
\alpha=k \cos \theta, \quad \beta=k \sin \theta
$$

で与えられ， $\beta$ は Snell の法則により定数である. $c(\sigma)$, $s(\sigma)$ はそれぞれ Fresnel cos, sin 関数である. 座標系は 2. で述べた系と同じとする. $y \rightarrow \pm \infty$ に対応して $\sigma \rightarrow$ $\pm \infty$ となり式 (2) はとれぞれ完全反射波と入射波の合 成解, 入射波だけの解に一致する. 図一2 は実験と同じ

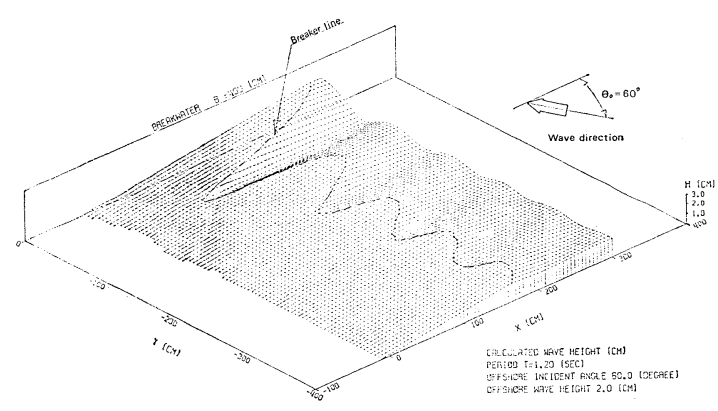

図一2 波高計算結果

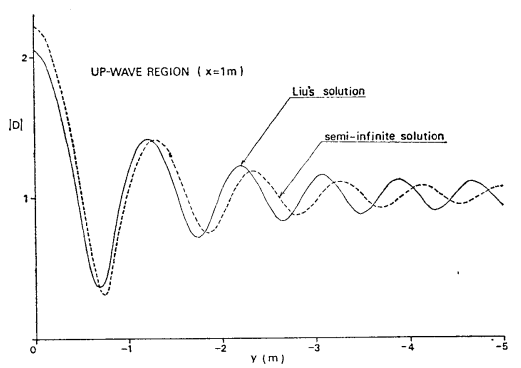

図一3 回折係数 $|D|$ の比較 (up-wave region)

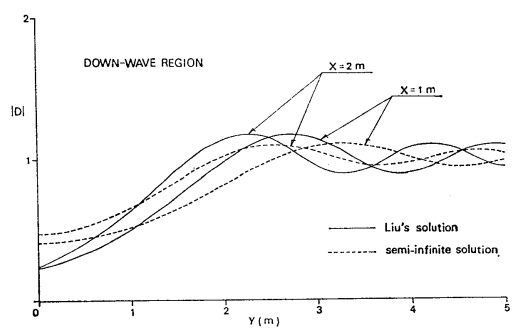

図-4 回折係数 $|D|$ の比較 (down-wave region)

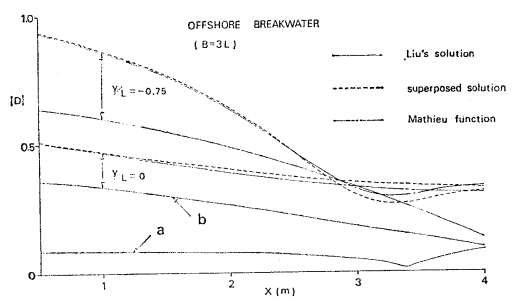

図一5 回折係数 $|D|$ の比較（離岸堤）

条件で計算した結果である. 式 (2) の解の性質を調べる ために, 水深一定とした半無限堤の回折解と比較した結 果が 図一3，4 で両者は良く一致し，その差は斜面上の 波長減少比に比較して，僅かである．但し離岸堤を $X=$ $4 \mathrm{~m}$ に設置し，そこでの波長を $L$ とした時, 離岸堤長 $B$ を $3 L$ とした場合の計算結果と, 半無限堤の合成解 及び Mathieu function による解とを比較した図一5で はかなりの相違が見られる。 また離岸堤中央, $y / L=0$ で $y$ の正側から計算した $a$ と, 負側から計算した $b$ が 一致せず，波長に比べて離岸堤長が短い場合は問題点が 残っている.

\section{4. 突堤の UP-WAVE REGION 側の流れの 計算法}

流れの運動量方程式を以下に記す.

$$
\left.\begin{array}{r}
C_{f} \rho U_{0} U=-\rho g(\bar{\eta}+h) \frac{\partial \bar{\eta}}{\partial x}-\left(\frac{\partial S_{x x}}{\partial x}+\frac{\partial S_{x y}}{\partial y}\right) \\
C_{f} \rho U_{0} V=-\rho g(\bar{\eta}+h) \frac{\partial \bar{\eta}}{\partial y}-\left(\frac{\partial S_{x y}}{\partial x}+\frac{\partial S_{y y}}{\partial y}\right)
\end{array}\right\}
$$

$C_{f}$ : 摩擦係数, $h:$ 水深, $\bar{\eta}$ : 平均水位.

$U_{0}$ は底面軌道流速の振幅を用い,

$$
U_{0}=A \omega / \sinh k h
$$

とする. 砕波帯外では radiation stress は set-down と バランスするとし，流れの強制力としては作用しないと 考える. $\bar{\eta}_{c}$ は流れの存在による水位の変化と定義し, total depth $d$ を

$$
d=\bar{\eta}+h\left(x \leqq x_{B}\right), \quad d=\bar{\eta}_{c}+h\left(x>x_{B}\right) \cdots
$$

とする. Stream function $\phi$ を以下のように定義する.

$$
d \cdot U=-\phi_{y}, \quad d \cdot V=\phi_{x}
$$

式(2)のポテンシャルから水粒子流速を計算し, radiation stress の定義式 (例光ば Phillips ${ }^{4)}$ ) に代入すれば, 反射波の影響を考虑できる. 比較のために反射波により 完全重複波が形成される場合の結果も併せて表一2に示 した.（III）の radiation stress の各成分は， $\sigma \rightarrow \pm \infty に$ 
表一2 波条件の異なる場合の radiation stress

\begin{tabular}{|c|c|c|c|}
\hline & (I) 単一入射诐 & （II）入射波と完全反射波 & （III）入射波と回折を伴ら反射波 \\
\hline$S_{x x}$ & $\begin{array}{l}E\left\{\frac{C_{g}}{C}\left(1+\cos ^{2} \theta\right)\right. \\
\left.-\frac{1}{2}\right\}\end{array}$ & $\begin{aligned} E_{1} & \left\{\frac{C_{g}}{C}\left(1+\cos ^{2} \theta\right)-\frac{1}{2}\right\} \\
& +\frac{1}{2} \rho g a^{2} \sin ^{2} \theta\left\{1-\left(\frac{2 C_{g}}{C}-1\right) \cosh 2 k h\right\} \\
& \cdot \cos 2 \beta y\end{aligned}$ & $\begin{aligned} E_{2} & \left\{\frac{C_{g}}{C}\left(1+\cos ^{2} \theta\right)-\frac{1}{2}\right\}+\frac{1}{2} \rho g a^{2} \sin ^{2} \theta\left\{1-\left(\frac{2 C_{g}}{C}-1\right)\right. \\
& \cdot \cosh 2 k h\} \cdot \frac{1}{2}\left[\sqrt{2}\left\{\frac{1}{2}+C(\sigma)\right\} \cos \left(2 \beta y+\frac{\pi}{4}\right)\right. \\
& \left.+\sqrt{2}\left\{\frac{1}{2}+S(\sigma)\right\} \cdot \sin \left(2 \beta y+\frac{\pi}{4}\right)\right]\end{aligned}$ \\
\hline$S_{y y}$ & $\begin{array}{l}E\left\{\frac{C_{g}}{C}\left(2-\cos ^{2} \theta\right)\right. \\
\left.-\frac{1}{2}\right\}\end{array}$ & $\begin{aligned} E_{1} & \left\{\frac{C_{g}}{C}\left(2-\cos ^{2} \theta\right)-\frac{1}{2}\right\} \\
& +\frac{1}{2} \rho g a^{2} \sin ^{2} \theta\left\{1-\left(\frac{2 C_{g}}{C}-1\right) \cosh 2 k h\right. \\
& \left.-\frac{4 C_{g}}{C}\right\} \cdot \cos 2 \beta y\end{aligned}$ & $\begin{aligned} E_{2} & \left\{\frac{C_{g}}{C}\left(2-\cos ^{2} \theta\right)-\frac{1}{2}\right\}+\frac{1}{2} \rho g a^{2} \sin ^{2} \theta\left\{1-\left(\frac{2 C_{g}}{C}-1\right)\right. \\
& \left.\cdot \cosh 2 k h-\frac{4 C_{g}}{C}\right\} \cdot \frac{1}{2}\left[\sqrt{2}\left\{\frac{1}{2}+C(\sigma)\right\} \cos \left(2 \beta y+\frac{\pi}{4}\right)\right. \\
& \left.+\sqrt{2}\left\{\frac{1}{2}+S(\sigma)\right\} \cdot \sin \left(2 \beta y+\frac{\pi}{4}\right)\right]\end{aligned}$ \\
\hline$S_{x y}$ & $-E \frac{C_{g}}{C} \sin \theta \cos \theta$ & 0 & $\begin{array}{l}-E_{C}^{C_{g}} \sin \theta \cos \theta \cdot\left[1-\frac{1}{2}\left\{\frac{1}{2}+C(\sigma)\right\}^{2}\right. \\
\left.-\frac{1}{2}\left\{\frac{1}{2}+S(\sigma)\right\}^{2}\right]\end{array}$ \\
\hline Energy & $E=\frac{1}{2} \rho g a^{2}$ & $E_{1}=\frac{1}{2} \rho g(2 a \cos \beta y)^{2}$ & $E_{2}=\frac{1}{2} \rho g(a|D|)^{2}$ \\
\hline
\end{tabular}

対応してそれぞれ（II)，（I）に一致する.（II）の $S_{x x}$ ， $S_{y y}$ は $y$ 方向に変化するが，平均すると，入射波の radiation stress（I）の正確に 2 倍になる. 又, 長波近 似が可能であれば，(II）及び（III）の $S_{x x}, S_{y y}$ の $\sin ^{2} \theta$ の項は無視でき，反射波と入射波の合成振幅を単 一入射波の $S_{x x} ， S_{y y}$ に代入した結果と一致する. $S_{: x y}$ については符号の関係からこの様な取扱いができない点 に注意する必要がある。 。

砕波帯内で合成振幅 $A$ を

$$
A=a|D|=\gamma d \text {. }
$$

と仮定し，長波近似を用いると表一2（III）の $S_{x x}, S_{y y}$ は

$$
S_{x x}=\frac{3}{4} \rho g \gamma^{2} d^{2}, \quad S_{y y}=\frac{1}{4} \rho g \gamma^{2} d^{2}
$$

となる. $S_{x y}$ 成分には入射波振幅 $a$ が含まれており，碎 波带内の合成振幅より分離しなくてはならない，Liu and $\mathrm{Mei}^{1)}$ は砕波帯内でも回折係数 $|D|$ が消滅しないと 考光，式(9)より，

$$
a=\gamma d /|D| \cong \gamma d /|D|_{B}
$$

としている．但し $|D|_{B}$ は砕波線上の值で，式を簡略に するための近似である. 式 (11) より $S_{x y}$ は

$$
\begin{aligned}
& S_{x y}=\frac{1}{2} \rho g^{3 / 2} \gamma^{2}\left(\frac{\sin \theta}{c}\right)_{0} d^{5 / 2} \cdot F(y), \\
& F(y)=\left[\frac{1}{2}\left\{\frac{1}{2}+c(\sigma)\right\}^{2}\right. \\
& \left.+\frac{1}{2}\left\{\frac{1}{2}+s(\sigma)\right\}^{2}-1\right]_{\sigma=\sigma_{B}} /|D|_{B}^{2}, \\
& F^{\prime}(y)=\left[\frac{1}{2}\left\{\frac{1}{2}+c(\sigma)\right\}^{2}\right. \\
& \left.+\frac{1}{2}\left\{\frac{1}{2}+s(\sigma)\right\}^{2}-1\right]_{\sigma=\sigma_{B}}
\end{aligned}
$$

となる．但し式 (11) で $|D|_{B}$ が 1 より小さい場合， $a$ は合成振幅 $\gamma d$ より大きくなり現実には存在し得ない振 幅であることに注意する必要がある。式 (10)，(12）を 式(4)に代入し， $U_{0}$ に長波近似を行い，式(5) では定 数 $\bar{U}_{0}$ を用いて整理すると，

$$
\left.f \begin{array}{rl}
\nabla^{2} \phi= & f \quad \frac{g^{1 / 2} d^{1 / 2}}{C_{f} \gamma} \cdot\left[-1.5 d_{y} h_{x}\right. \\
& +\gamma^{2}\left(1.5 d_{x} d_{y}+d d_{x y}\right)-\frac{5}{4} g^{1 / 2}\left(\frac{\sin \theta}{c}\right)_{0} \gamma^{2} \cdot \\
& \left\{2\left(d_{x^{2}}-d_{y}^{2}\right) d^{1 / 2} F+d^{3 / 2}\left(d_{x x}-d_{y y}\right) F\right. \\
- & \left.\left.\frac{11}{5} d^{3 / 2} d_{y} F_{y}-\frac{2}{5} d^{5 / 2} F_{y y}\right\}\right] \quad\left(x \leqq x_{B}\right) \\
= & -\frac{2 g h}{C_{f} \bar{U}_{0}} h_{x} \frac{\partial d}{\partial y} \quad\left(x>x_{B}\right)
\end{array}\right\}
$$

が得られる. 式(13)の第 1 式右辺の各項は, それぞれ 平均水位 $\bar{\eta}, S_{x x}, S_{y y}$ 成分, $S_{x y}$ 成分によるものであ る. $f$ の正負が循環流を形成し, その符号之流孔の向き は表一3 のようになる.

表一3 $f$ の正負と循環流の向きの関係

\begin{tabular}{c|c|c}
\hline & $f$ & 正 \\
\hline$\phi$ & 負 & 負 \\
\hline 流 向 & 反時計回り & 正 \\
\hline
\end{tabular}

斜めに入射する単一入射波の沿岸流は

$$
V=\frac{5}{4} \frac{g \gamma}{C_{f}}\left(\frac{\sin \theta}{C}\right)_{0} \frac{S}{1+\frac{3}{2} \gamma^{2}} d
$$

で与えられ，沿岸方向の一端の境界条件とする，他端は 
突堤部分で $V=0$, 突堤先端と沖側境界までは, 連続条 件を考虑して, 流出する流速を沖に向かって減少する三 角形分布とする.

砕波帯内の total depth $d$ の初期值は, 直角入射波を 仮定した set-up を考慮し

$$
\left.\begin{array}{l}
d=\bar{\eta}+h=\frac{S}{1+\frac{3}{2} \gamma^{2}}\left(x-x_{S}\right), \\
x_{S}=-\left\{\left(1+\frac{3}{2} \gamma^{2}\right)\left(1-\frac{\gamma^{2}}{4}\right)-1\right\} \cdot x_{B} \quad\left(x \leqq x_{B}\right) \\
d=\bar{\eta}_{c}+h=S x \quad\left(x>x_{B}\right)
\end{array}\right\}
$$

とする. 一方, 式(4), (5) からそれぞれ $d_{x}$ を求めるこ とができ， $\phi$ が既知であれば $d$ を修正することが可能 である，但し式の性質から $d_{x}$ を陽に解く事はできず繰 返し計算が必要である。

\section{5. 計算結果と検討}

図一6 が計算結果の一部拡大図で, $C_{f}=0.01$ とし, $d$ の iteration は行なっていない. 図一1 と比較すると沿

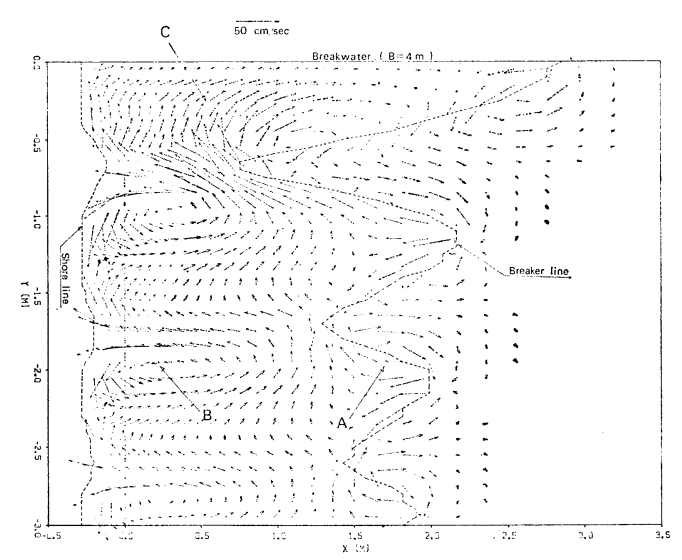

図一6 流れの計算結果

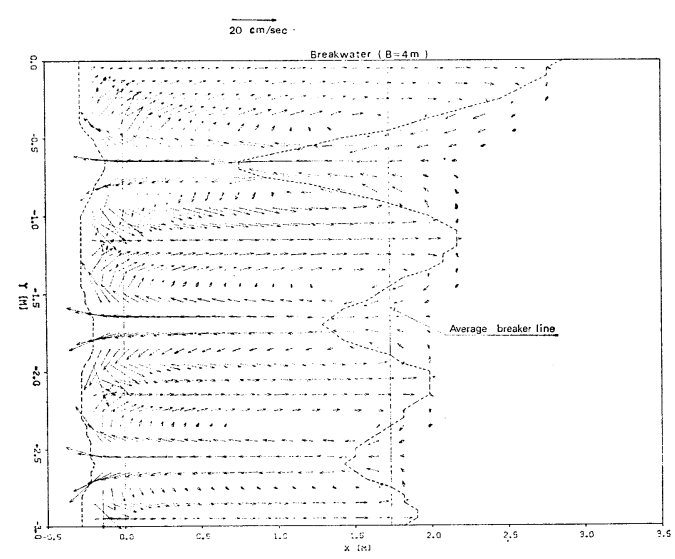

図一7 $S_{x x}, S_{y y}$ 成分による流れの計算結果

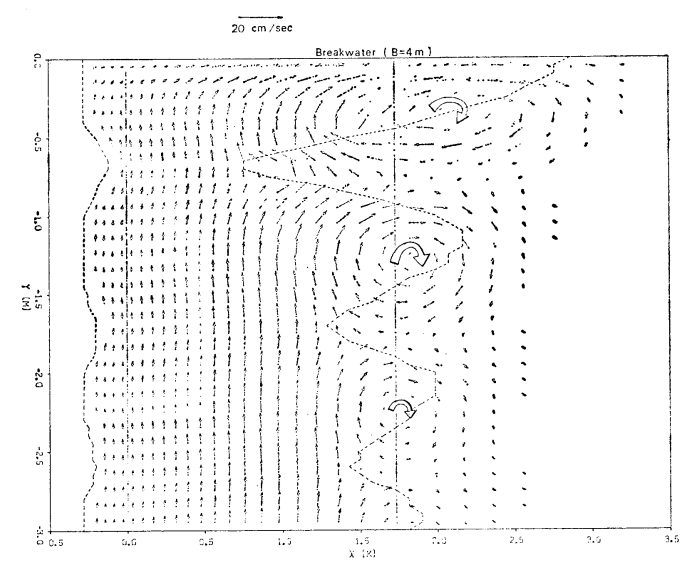

図一8 $S_{x y}$ 成分による流れの計算結果

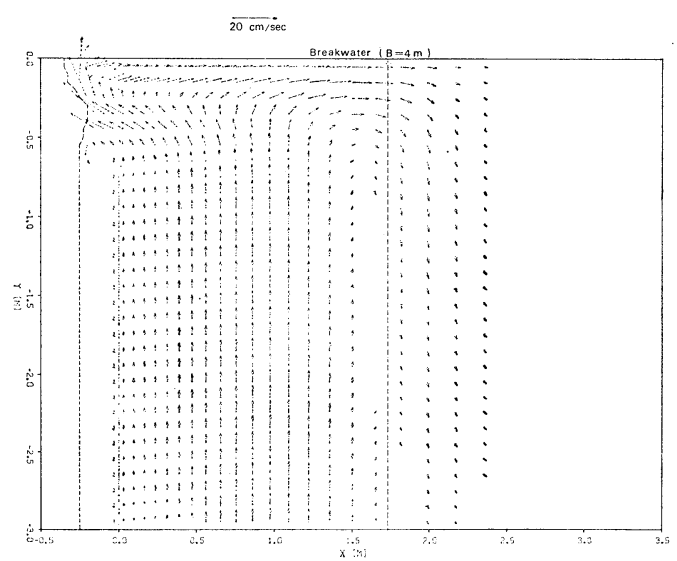

図一9 単一入射波（反射波省略）に上る沿岸流の 流況

岸流の流れ方に本質的な相違が見られ, 突堤基部の C 付 近の流れが逆向である、砕波線の変動に伴い， A, B の ように流れは二重構造 (堀川・丸山吕) を形成する.

原因を追求するため式 (14)の $S_{x y}$ 成分, 即ち第 3 項 を省略し，全境界 $\phi=0$ として計算した結果が 図一7で ある. 但し set-down による微分不連続性を消去し, 砕 波帯内の $d$ の勾配に関する性質を(16) 式と同じにする ため, $d$ を

$$
d=\frac{S x_{B}}{\left(x_{B}-x_{S}\right)}\left(x-x_{S}\right) \quad\left(x \leqq x_{B}\right)
$$

としている. 図一6,7を比較すると, rip current A は 後者において消滅し，その発生原因が set-down による 微分不連続性によるものであることがわかる， B，Cの 流れは両者に打いて明確に見られ，この流れが $d$ の $y$ 方向勾配により発生した事が理解でさる. 式 (16)の $d$ は砕波帯幅が増加する場合, 砕波線上及び近傍で setdown のために $y$ 方向勾配 $d_{y}$ は負で, 汀線近くでは 逆に set-up のために $d_{y}$ は正になる. 式 (13) の第 1 式 
表一4 砕波帯幅が増加する場合に形成される 循環流の向き

\begin{tabular}{|c|c|c|}
\hline 式 (16) $d$ の $y$ 方向勾配 & 第 1 項の作用 & 第 2 項の作用 \\
\hline 碀波線上扰よび近傍， $d y<0$ & 反時計回り & 時計回り \\
\hline 汀線の近傍, $d y>0$ & 時計回り & 反時計回り \\
\hline
\end{tabular}

右辺の第 1 項，第 2 項の $d_{y}$ の符号が逆であることによ り，循環流形成に与える作用は逆で表一3 の関係を考慮 すると表-4 のようにまとめることがでさる. 表一4 と 図一6 を対比すると，流れが第 1 項の作用で支配されて いることが明らかで， $S_{x x}, S_{y y}$ の radiation stress は循 環流の形成に見かけ上寄与しない事になる.これは $\gamma^{2}$ のために第 2 項が order 的に小さいためである.

図一8 は $S_{x y}$ による沿岸流だけの計算結果で， $d$ は 式(17) で与え set-downの影響を消去している， $S_{x y}$ 成 分によっても循環流が形成され，その原因が $a$ を式(11) と仮定したためで, $y$ 方向の 2 階偏微分が主要な強制力 になっているのである. 比較のために，単一入射波によ り生ずる沿岸流が突堤の影響でどの様に流れるかを示し た結果が図一9で，いずれの場合も沿岸流が岸より剝離 する現象を再現できない.この計算例では， $d$ の iterationを行っており, 流れの向きの岸, 沖方向に対応し て, 汀線は初期值よりそれぞれ前進, 後退することが確 認されている.

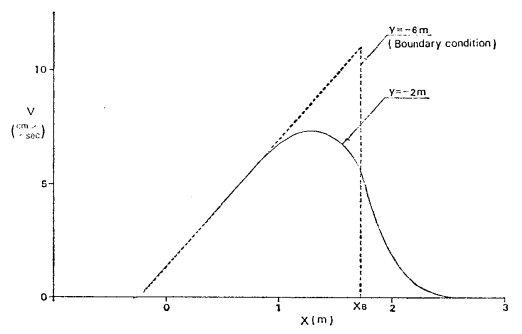

図一10 数值計算上現われる見かけの拡散項

今後拡散項まで含めた計算が必要となるであろうが， 式 (4)，(5)によっても数值計算上，見かけの拡散項が現 われる. 図一10は式(15)を沿岸方向の両境界条件とし て，単一入射波による沿岸流の発達を計算した結果であ るが，定常解は Longuet-Higgins ${ }^{3)}$ の解と類似し，式の 差分化による誤差の一種である.

\section{6. 結 論}

Liu and $\mathrm{Mei}^{1)}$ の流れのモデル化は，研波炗内の波高
分布に式 (9) を仮定した場合の徹底したモデルであり， この意味では完結したものであると思われる. しかし循 環流の形成は空間的な波高, 即ち $d$ の $y$ 方向微分の作 用であり， $d$ の初期值を直角入射波の一次元的な setup, set-down で決定するのは論理的に無理がある. し かもこの $d$ の初期值で流れが決定的に支配され，その 流れによる水深 $d$ の修正は初期值の不自然さが反映さ れ不安定で結果は不自然なものになる.

水口 ${ }^{6)}$ の (A) モデルに関する記述は式 (14) の第 1 式 右辺第 2 項に相当するものであるが，砕波線上の radiation stress の $y$ 方向勾配を, set-down の $y$ 方向勾配 と考える Liu and $\mathrm{Mei}^{1}$ のモデルでは結果が逆になり， 砕波帯の狭い所で岸向き，広い所で沖向きの循環流が形 成される.

今回の報告では沿岸流の突堤による剝離現象を解明し 得なかったが，Liu and $\mathrm{Mei}^{\mathrm{i})}$ のモデルの問題点を洗い 出すことはできたと思う.今後 radiation stress による set-up, set-down 及び流れの関係を再検討し, より合理 的なモデルを開発することが必要であろう.

最後に実験及びその他で協力を得た八重州土木の下田 隆男君, 流れについて discussion を行った中央大学の 水口優講師，以上の諸氏に謝意を表す.

\section{参 考文 献}

1) Liu, P. L. F. and C. C. Mei: Effects of a breakwater on near-shore currents due to breaking waves, Tech. Rep. 192, R. M. Parsons Lab., Mass. Inst. of Technol., Cambridge, 1974.

2) Galvin, C. J. and P. S. Eagleson: Experimental study of longshore currents on a plane beach, U. S. Army Coast. Eng. Res. Center, Tech. Mem. 10, pp. 1-80, 1965.

3) Longuet-Higgins, M. S.: Longshore currents generated by obliquely incident sea waves, 1 and 2 , J. Geophys. Res., 75, pp. 6778-6789, 6790-6801, 1970.

4) Phillips, O. M.: The Dynamics of the Upper Ocean, Cambridge, Univ. Press, Cambridge, 261 p, 1969.

5）堀川清司・丸山康樹：室内実験に打けるリップ・ カレントの発生について, 第 23 回海講論文集, pp. 464-469, 1976.

6）水口優・海浜循環流のメカニズムについて，第 24 回海講論文集, pp. 591-595, 1977. 